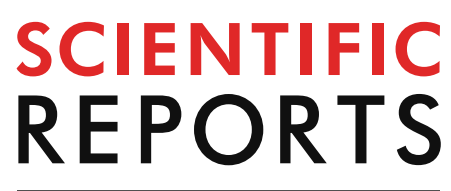

natureresearch

Check for updates

\title{
Incidence, reasons, and risk factors for 30-day readmission after lumbar spine surgery for degenerative spinal disease
}

\author{
Pyung Goo Cho ${ }^{1}$, Tae Hyun Kim², Hana Lee ${ }^{3}$, Gyu Yeul Ji3 ${ }^{3}$, Sang Hyuk Park ${ }^{4}$ \& Dong Ah Shin ${ }^{3 凶}$
}

This study investigated risk factors for 30-day readmission of discharged patients who had undergone lumbar spinal surgery. This retrospective, case-control study reviewed 3,933 patients discharged after elective spinal surgery for lumbar degenerative diseases from 2005 to 2012 at a university hospital. Of these patients, 102 were re-hospitalized within 30 days of discharge. Patient medical records were reviewed. The incidence of readmission within 30 days was $2.6 \%$, and uncontrolled pain was the most common reason for readmission. In the univariate analysis, age, mental illness, the number of medical comorbidities, previous spinal surgery, fusion surgery, number of fusion levels, estimated blood loss, operation time, intensive care unit (ICU) admission, length of hospital stays, and total medical expenses were associated with a higher risk of readmission within 30 days. Multiple logistic regression analysis revealed that previous spinal surgery, operation time, ICU admission, length of hospital stays, and total medical expenses were independent risk factors for 30-day readmission. Independent risk factors for readmission were longer operation time, a previous spinal surgery, ICU admission, longer hospital stays, and higher medical expenses. Further studies controlling these risk factors could contribute to reducing readmission and thus improving the quality of care.

Surgical treatment of the spine has increased rapidly in recent decades and has been accompanied by increasing costs. ${ }^{1}$ The growth rate of spinal surgery is higher than expected, even after adjusting for the aging population..$^{2,3}$ There is growing interest in advanced technology and equipment, which allow for more complex spinal surgeries but also lead to additional complications and costs. ${ }^{4}$ Unfortunately, the higher rate of spinal surgery is also associated with lower patient satisfaction. ${ }^{5}$

There is increasing awareness that management strategies are needed to improve the results of spine surgery while controlling costs. Lack of management of the quality of healthcare during treatment increases unplanned risks. ${ }^{6}$ One helpful indicator of healthcare quality is readmission within 30 days of surgery. ${ }^{7,8}$ Readmission under certain circumstances is related to errors in initial treatment. As such, early readmission can be used as an indicator of treatment quality. $7,9,10$

Previous studies have examined readmission rates after spinal surgery ${ }^{6,70-22}$ However, few studies in this area have focused on patients in Asian countries, such as the Republic of Korea. Racial differences are known to exist in 30-day readmission rates after spinal surgery ${ }^{23}$ If risk factors for readmission rates can be determined, including demographic, clinical, and therapeutic profiles, clinicians may be able to reduce readmission rates. To this end, the present study investigated the risk factors for readmission of discharged patients who underwent lumbar spinal surgery.

\section{Methods}

Subjects. This was a retrospective analysis of data collected between Jan. 2005 and Dec. 2012 at a single neurosurgery department in a 2,266-bed tertiary hospital with six spine surgeons. Data were obtained using private surgical data base of spine center in Severance hospital. Institutional Review Board approval of Sever-

${ }^{1}$ Department of Neurosurgery, Ajou University College of Medicine, Suwon, Republic of Korea. ${ }^{2}$ Graduate School of Public Health, Yonsei University, Seoul, Republic of Korea. ${ }^{3}$ Department of Neurosurgery, Yonsei University College of Medicine, 50 Yonsei-ro, Seodaemun-gu, Seoul 120-752, Republic of Korea. ${ }^{4}$ Department of Neurosurgery, Seoul Now Hospital, Seongnam, Republic of Korea. ${ }^{\circledR}$ email: cistern@yuhs.ac 
ance Hospital, Yonsei University College of Medicine, was obtained before study initiation (Approval number: 4-2013-0605).

All variables were investigated through patient medical records, a private surgical database, and telephone interviews. Due to the retrospective nature of the study, the Institutional Review Board has confirmed that prior informed consent is not required. Patients were included in the study if they underwent elective spine surgery for lumbar degenerative disease and experienced unplanned readmission within 30 days of discharge. Lumbar degenerative disease included herniated disc disease, degenerative disc disease, spinal stenosis, spondylolisthesis, or spinal instability. The readmission group was captured using the computational algorithm that extracts all patients with 30-day readmission after an index spine surgery. In addition, telephone interviews were conducted to identify cases of readmission to other hospitals. A total of 9,587 patients underwent spine surgery at our institute during the study period. Some patients underwent multiple operations at the same time; however, they were counted as one. Among them, 3,933 patients underwent elective lumbar spine surgery, and $102(2.6 \%)$ patients had unplanned readmission within 30 days of discharge after the initial operation. The control group $(n=487)$ was sampled by the propensity score matching using the 3 variables: sex, insurance type, and type of degenerative disease, with a ratio of 5 controls to 1 case. Patients were excluded if they underwent planned readmission for a second treatment, or another surgery not associated with the first surgery. Planned anti-cancer therapy and planned second surgeries were categorized as planned readmission and were excluded from the data. A total of 102 hospitalized patients were matched 1: 5 and initially 510 were extracted. However, 23 patients with data problem were excluded from the control group.

Variables. The independent variables evaluated in this study were selected on the basis of previous research. ${ }^{6,24,25}$ The causes of readmission were categorized as surgical reasons directly related to the initial surgery and non-surgical reasons indirectly related to the initial surgery. The variables were categorized according to demographic, clinical, and therapeutic profiles. Demographic data including sex, age at surgery, type of insurance, marital status, educational level, and residential area were analyzed. Insurance type was categorized as health insurance, medical aid, or other. Residential area was categorized as the same city as our institute (Seoul), a neighboring city that shared a border with Seoul, or another, more distant city. Clinical profiles including comorbidities, previous spinal surgery, mental illness, and the number of comorbidities were analyzed. Comorbidities included hypertension, diabetes, hepatitis, pulmonary tuberculosis, coronary artery disease, and other. Mental illness included depression, anxiety disorder, somatoform disorder, and other disorders diagnosed by psychiatrists. There was a maximum of five comorbidities per patient. The number of comorbidities was categorized from 0 to $3+$ and analyzed as categorical variables. For therapeutic profiles, the type of surgery, level of surgery, operative level, blood loss, operation time, medical expense, length of stays in the hospital, admission to the intensive care unit (ICU), and surgeon experience were analyzed. Surgical approaches were categorized as anterior, posterior, lateral, and mixed.

Statistical analysis. Parametric data were expressed as mean \pm standard deviation and were compared using Student $t$-tests. Nonparametric data were expressed as medians and compared using Mann-Whitney U tests. Chi-Square tests were used to analyze categorical variables. To identify factors for readmission, we performed multiple logistic regression analysis, which included all previously analyzed variables that were statistically significant. We examined the value of the variation inflation factor (VIF) to see if there was multicollinearity between the variables. The VIF analysis did not include adverse events (AE). And only variables with the VIF less than 10 were used in this study. We used SAS software for Windows (SAS Institute Inc., Cary, NC) for the statistical analyses. $P<0.05$ was considered statistically significant.

\section{Results}

Reasons for readmission. Surgical reasons for readmission included uncontrolled pain (24\%), recurrence of disc herniation or major symptoms $(12 \%)$, wound dehiscence $(9 \%)$, instrument failure (8\%), wound infections $(6 \%)$, postoperative hematoma (3\%), neurogenic bladder $(2 \%)$, cerebrospinal fluid (CSF) leakage (2\%), and postoperative paralysis (1\%). Non-surgical reasons included gastrointestinal diseases (12\%), cardiovascular diseases (7\%), neurologic diseases (4\%), pulmonary diseases (3\%), urologic diseases (3\%), psychological diseases (3\%), and drug-related complications (1\%). (Fig. 1).

Risk factors for readmission. In the univariate analysis, age, mental illness, the number of medical comorbidities, previous spinal surgery, fusion surgery, number of fusion levels, estimated blood loss, operation time, ICU admission, length of hospital stay, and medical expenses were associated with a higher 30-day readmission rate (Table 1).

However, multiple logistic regression analysis showed that operation time (Odds ratio [OR] 1.595, 95\% confidence interval [CI] 1.591-2.054, $P=0.046$ ), previous spinal surgery (OR 2.519, 95\% CI 1.075-5.094, $P=0.033$ ), ICU admission (OR 1.935, 95\% CI 1.753-2.425, $P=0.008$ ), length of hospital stays (OR 1.447, 95\% CI 1.412-1.920, $P=0.004$ ), and medical expenses (OR 1.470, 95\% CI 1.423-1.879, $P=0.001$ ) were independent predictors of readmission within 30 days (Table 2). Risk factors with odds ratio above 2.0 is previous spinal surgery. Risk factors with odds ratios between 1.0 and 2.0 are: operation time, ICU admission, length of hospital stays, and medical expenses. 


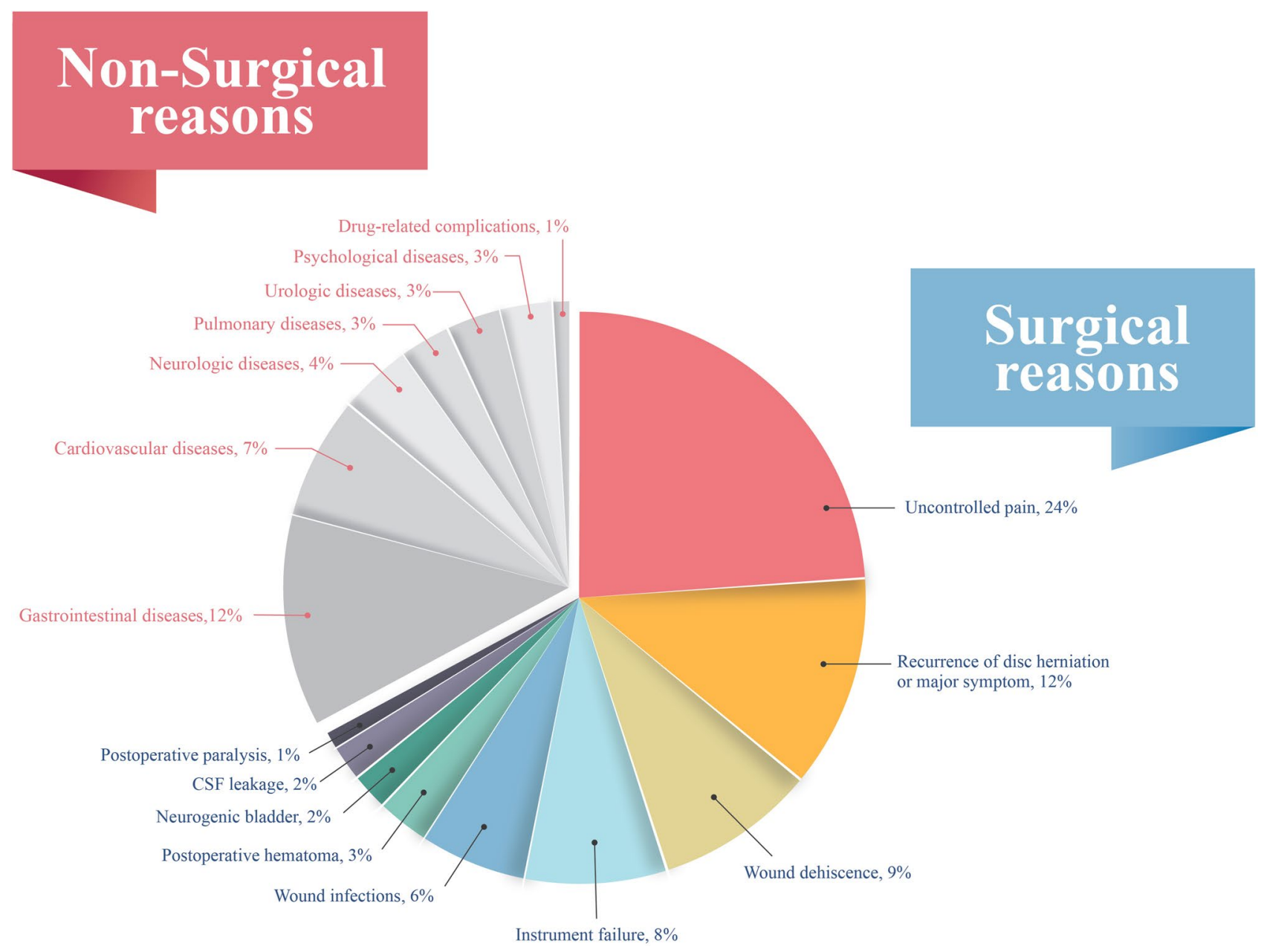

Figure 1. The causes of readmission after lumbar spinal surgery.

\section{Discussion}

This is a retrospective analysis of readmission. Previous studies have reported readmission rates after spine surgery. ${ }^{6,7,10-22}$ Most of these studies were retrospective cohort studies that used public databases. Although Korea also has a public database for its National Health Insurance, which covers $98 \%$ of the overall population, the accuracy of diagnostic data is an issue because of the nature of claims data. Claims data are not gathered for clinical purposes but rather to reimburse healthcare services. It is possible that the diagnostic information in claims data are susceptible to up-coding by providers seeking higher reimbursement rates. ${ }^{26}$ However, in our study, well-controlled data were collected from our private registry.

This study found a 30 -day readmission rate of $2.6 \%$. Compared with data from other published studies, our 30-day readmission rate was relatively low. ${ }^{6,10,12}$ A longer initial hospital stays (mean 13.3 days) compare to previous studies $^{27-29}$ (3.6-4.8 days) is considered to be the main reason for our low readmission rates, as early complications may have been detected during the initial hospital stays. In this study, $8 \%$ of patients were unable to interviewed due to phone number changing or refusal. The possibility of readmission to another hospital exists, which may be another reason for the relatively low readmission rate in this study. Among the 102 readmitted patients, $67 \%$ were readmitted for surgical reasons; $40 \%$ of these readmitted patients underwent another operation. The reasons for reoperation included recurrence $(8,30 \%)$, wound dehiscence $(8,30 \%)$, instrument failure $(8,30 \%)$, wound infection $(2,7 \%)$, and hematoma $(1,4 \%)$. In contrast to our results, previous studies have reported that non-surgical complications were the most common reasons for readmission, with only a minority of readmitted patients requiring reoperation. ${ }^{30-32}$ Although some previous studies have also cited infection as the most common cause for readmission, ${ }^{33}$ intractable pain was the most common reason for readmission in our study. Adogwa et al. ${ }^{30}$ also found that intractable pain was the most common reason for readmission. While early infection can be identified during the postoperative hospital stays, after discharge with routine medications of lower intensity, rebound pain with or without recurrence can be a major problem. Better education and medications given as needed might be a way to prevent readmission for intractable pain.

Among demographic variables, age was the only factor that was significantly associated with readmission in the univariate analysis. Previous studies have also identified age as a factor that increases the risk of readmission. ${ }^{9,21,22,34}$ Therefore, a multidisciplinary approach should be undertaken in older patients to reduce readmission and improve healthcare quality. ${ }^{9,21,22}$ Among clinical variables, previous spinal surgery, mental illness, and the 


\begin{tabular}{|c|c|c|c|c|}
\hline Category & Variable & $\begin{array}{l}\text { Readmission group }(\mathrm{n}=102) \text {, } \\
\mathrm{n}(\%)\end{array}$ & Control group $(n=487), n(\%)$ & $P$ \\
\hline \multicolumn{5}{|l|}{ Demographic variables } \\
\hline Age & Years & $59.3 \pm 15.1$ & $54.7 \pm 14.1$ & $<0.001^{\star}$ \\
\hline \multirow{2}{*}{ Sex } & Male & $52(51.0)$ & $250(51.3)$ & 0.948 \\
\hline & Female & $50(49.0)$ & $237(48.7)$ & \\
\hline \multirow{2}{*}{ Marital status } & Married & $96(94)$ & $444(91.2)$ & 0.413 \\
\hline & Single & $6(6)$ & $43(8.8)$ & \\
\hline \multirow{3}{*}{ Education } & University or higher & $27(26.5)$ & $179(36.8)$ & 0.387 \\
\hline & High school & $48(47)$ & $194(39.8)$ & \\
\hline & Junior high or lower & $27(26.5)$ & $114(23.4)$ & \\
\hline \multirow{3}{*}{ Insurance type } & Health insurance & $92(90.1)$ & $464(95.3)$ & 0.135 \\
\hline & Medical aid & $6(5.9)$ & $14(2.9)$ & \\
\hline & Other & $1(1.0)$ & $9(1.8)$ & \\
\hline \multirow{3}{*}{ Residence } & Seoul & 57 (55.9) & $209(42.9)$ & 0.595 \\
\hline & Neighboring city & $25(24.5)$ & $144(29.6)$ & \\
\hline & \begin{tabular}{|l|} 
Other city \\
\end{tabular} & 20 (19.6) & $134(27.5)$ & \\
\hline \multicolumn{5}{|l|}{ Clinical variables } \\
\hline Mental illness & & $12(11.8)$ & $12(2.5)$ & $<0.001^{*}$ \\
\hline \multirow{4}{*}{$\begin{array}{l}\text { Number of medical co-morbid- } \\
\text { ities }\end{array}$} & 0 & $30(29.4)$ & $281(47.7)$ & $<0.001^{\star}$ \\
\hline & 1 & $36(35.3)$ & $215(36.5)$ & \\
\hline & 2 & $26(25.5)$ & $73(12.4)$ & \\
\hline & $>3$ & $10(9.9)$ & $20(3.4)$ & \\
\hline Previous spinal surgery & & $26(25.5)$ & $61(12.15)$ & $<0.001^{*}$ \\
\hline \multicolumn{5}{|l|}{ Therapeutic variables } \\
\hline Non-fusion surgery & & $33(32.4)$ & $220(45.2)$ & $0.017^{x}$ \\
\hline Fusion surgery & & 69 (67.6) & $267(54.8)$ & $0.017^{\star}$ \\
\hline Number of fusion levels & & $1.5 \pm 1.7$ & $1.0 \pm 1.2$ & $<0.001^{\star}$ \\
\hline \multirow{4}{*}{ Surgical approach } & Anterior & $23(22.6)$ & $142(29.2)$ & 0.205 \\
\hline & Posterior & $76(74.5)$ & $337(69.2)$ & \\
\hline & \begin{tabular}{|l|} 
Lateral \\
\end{tabular} & $0(0)$ & $4(0.8)$ & \\
\hline & Mixed & $3(2.9)$ & $4(0.8)$ & \\
\hline Blood loss (cc) & & $898.8 \pm 1572.7$ & $432.1 \pm 653.5$ & $<0.001^{*}$ \\
\hline Operation time (min) & & $263.4 \pm 118.8$ & $203.0 \pm 86.8$ & $<0.001^{\star}$ \\
\hline ICU admission & & $22(21.6)$ & $11(2.3)$ & $<0.001^{\star}$ \\
\hline Length of hospital stays & & $16.4 \pm 14.7$ & $12.7 \pm 13.4$ & $0.013^{*}$ \\
\hline Medical expenses (won) & & $11,660,000 \pm 6,784,400$ & $4,463,307 \pm 2,377,078$ & $<0.001^{\star}$ \\
\hline Surgeon experience & Years & $12.1 \pm 5.8$ & $12.6 \pm 5.6$ & 0.334 \\
\hline
\end{tabular}

Table 1. Independent risk factors for unplanned 30-day readmission related to the initial operation assessed by comparison of the readmitted group and the control group. ${ }^{\star}$ Statistically significant $(P<0.05)$.

number of comorbidities were statistically significant in the univariate analyses. Previous studies have identified comorbidities as factors that increase the rate of revision surgery or complicate revision surgery. ${ }^{22}$ Furthermore, patients suffering from mental illnesses had a higher risk of readmission. ${ }^{25,34,35}$ In the current study, a revision surgery was identified as a factor that increases the risk of readmission. Among published studies, the effect of previous spine surgery on readmission remains unclear; one study found that readmission was more common among patients with a history of additional procedures than among those without such a history, ${ }^{2}$ whereas another study found no relationship between a previous spine surgery and readmission. ${ }^{20}$

Among therapeutic profiles, medical expenses and length of hospital stays were the only variables that were significantly associated with readmission rates. Previous studies have also identified the number of fusion levels, length of hospital stays, and ICU admission as factors for readmission after spinal surgery. ${ }^{20,25}$ Some studies have found that the length of hospital stays increases the risk of readmission, while others have found that it reduces the risk of readmission. ${ }^{25}$ Identification of medical expenses as a factor for readmission is consistent with previous studies. Repeated hospitalization requires greater medical resources, leading to higher medical expenses. A previous study identified operation time, but not blood loss during surgery, as a factor for readmission, ${ }^{20}$ Similarly, operation time was significantly associated with readmission in this current study. Operation time is a factor for readmission, possibly because operation time is an indicator of the complexity of the surgery. ${ }^{36}$ Surgeons with greater experience tend to perform operations more rapidly and skillfully, so surgeon experience may be related to a shorter operation time. ${ }^{37}$ Surgeon, who has a lot of experience, is believed to reduce the readmission due to the reduced possibility of postoperative complication. ICU admission has been associated with increased risk 


\begin{tabular}{|l|l|l|l|l|l|}
\hline Category & Variable & $\boldsymbol{P}$ & Odds ratio & $\mathbf{9 5 \%}$ CI low & 95\% CI high \\
\hline Demographic variables & Age & 0.537 & 0.990 & 0.958 & 1.022 \\
\hline Clinical variables & Mental illness & 0.386 & 0.528 & 0.528 & 7.188 \\
\hline & Number of medical co-morbidities & 0.198 & 1.310 & 0.871 & 1.970 \\
\hline & Previous spinal surgery & $0.033^{*}$ & 2.519 & 1.075 & 5.094 \\
\hline Therapeutic variables & Non-fusion surgery & 0.358 & 0.262 & 0.214 & 0.562 \\
\hline & Fusion surgery & 0.179 & 0.462 & 0.154 & 1.387 \\
\hline & Number of fusion levels & 0.164 & 1.328 & 0.894 & 1.973 \\
\hline & Blood loss & 0.520 & 1.126 & 1.027 & 1.331 \\
\hline & Operation time & $0.046^{*}$ & 1.595 & 1.591 & 2.054 \\
\hline & ICU admission & $0.008^{*}$ & 1.935 & 1.753 & 2.425 \\
\hline & Length of hospital stays & $0.004^{*}$ & 1.447 & 1.412 & 1.920 \\
\hline & Medical expenses & $0.001^{*}$ & 1.470 & 1.423 & 1.879 \\
\hline & Surgeon experience & 0.418 & 0.975 & 0.917 & 1.036 \\
\hline
\end{tabular}

Table 2. Independent risk factors for unplanned 30-day readmission assessed by multiple logistic regression analysis. ${ }^{\star}$ Statistically significant $(P<0.05)$.

of readmission in previous studies. ${ }^{32}$ ICU admission is an indicator of the severity of the patient's condition due to medical complications and increased surgical difficulty; thus, patients admitted to the ICU should be given special care during hospitalization..$^{25}$

Previous studies have reported that patterns of medical care are influenced by the type of insurance and other socioeconomic factors. ${ }^{38,39}$ We expected that the type of insurance utilized would affect the readmission rate. However, we found no such relationship. We also expected that proximity to the hospital would be associated with a higher readmission rate, but we did not find any relationship between these two variables.

Several limitations of our study should be noted. First, this was a retrospective study performed via medical record review. Second, this study was conducted on patients who underwent spine surgery in a single hospital, so patients who were readmitted at another hospital were not accounted for. These could limit the validity of the data. Third, AE are the main cause of re-admission, however these were excluded from this study due to multicollinearity with other variables. We performed statistics on preliminary AE before conducting this study. Statistical results confirmed that multicollinearity problems occur when AE is directly included. The variables such as operation time, blood loss, length of stay and admission to ICU used in this study are factors that can be indirectly affected by AE. Because of this, not all AE have been eliminated. In future work, we will discuss the direct impact of $\mathrm{AE}$ on readmission.

\section{Conclusion}

The incidence of 30-day readmission after spine surgery was $2.6 \%$, and intractable pain was the most common reason for readmission. Multiple logistic regression analysis revealed that longer operation time, a previous spinal surgery, ICU admission, longer hospital stays, and higher medical expenses were independent risk factors for readmission. Further efforts to manage these risk factors will reduce readmission and thus improve quality of care.

Received: 12 September 2019; Accepted: 14 July 2020

Published online: 29 July 2020

\section{References}

1. Deyo, R. A. Back surgery-ho needs it?. N. Engl. J. Med. 356, 2239-2243. https://doi.org/10.1056/NEJMp078052 (2007).

2. Deyo, R. A., Mirza, S. K. \& Martin, B. I. Back pain prevalence and visit rates: estimates from U.S. national surveys, 2002. Spine 31, 2724-2727. https://doi.org/10.1097/01.brs.0000244618.06877.cd (2006).

3. Sivasubramaniam, V., Patel, H. C., Ozdemir, B. A. \& Papadopoulos, M. C. Trends in hospital admissions and surgical procedures for degenerative lumbar spine disease in England: a 15-year time-series study. BMJ Open 5, e009011. https://doi.org/10.1136/ bmjopen-2015-009011 (2015).

4. Deyo, R. A. et al. Use of bone morphogenetic proteins in spinal fusion surgery for older adults with lumbar stenosis: trends, complications, repeat surgery, and charges. Spine 37, 222-230. https://doi.org/10.1097/BRS.0b013e31821bfa3a (2012).

5. Keller, R. B., Atlas, S. J., Soule, D. N., Singer, D. E. \& Deyo, R. A. Relationship between rates and outcomes of operative treatment for lumbar disc herniation and spinal stenosis. J. Bone Joint Surg. 81, 752-762. https://doi.org/10.2106/00004623-199906000-00002 (1999).

6. McCormack, R. A. et al. An analysis of causes of readmission after spine surgery. Spine 37, 1260-1266. https://doi.org/10.1097/ BRS.0b013e318245f561 (2012)

7. Elsamadicy, A. A. et al. Patient body mass index is an independent predictor of 30-day hospital readmission after elective spine surgery. World Neurosurg. 96, 148-151. https://doi.org/10.1016/j.wneu.2016.08.097 (2016).

8. Rohr, R. Rehospitalizations among patients in the Medicare fee-for-service program. N. Engl. J. Med. 361, 311-312 (2009) ((author reply 312)).

9. Ashton, C. M., Kuykendall, D. H., Johnson, M. L., Wray, N. P. \& Wu, L. The association between the quality of inpatient care and early readmission. Ann. Intern. Med. 122, 415-421 (1995).

10. Lovecchio, F. et al. Predictors of thirty-day readmission after anterior cervical fusion. Spine 39, 127-133. https://doi.org/10.1097/ brs.0000000000000051 (2014). 
11. Akamnonu, C. et al. Unplanned hospital readmission after surgical treatment of common lumbar pathologies: rates and causes. Spine 40, 423-428. https://doi.org/10.1097/brs.0000000000000759 (2015).

12. Akins, P. T. et al. Risk factors associated with 30 -day readmissions after instrumented spine surgery in 14,939 patients: 30 -day readmissions after instrumented spine surgery. Spine 40, 1022-1032. https://doi.org/10.1097/brs.0000000000000916 (2015).

13. Basques, B. A., Varthi, A. G., Golinvaux, N. S., Bohl, D. D. \& Grauer, J. N. Patient characteristics associated with increased postoperative length of stay and readmission after elective laminectomy for lumbar spinal stenosis. Spine 39, 833-840. https://doi. org/10.1097/brs.0000000000000276 (2014).

14. Missios, S. \& Bekelis, K. Outpatient continuity of care and 30-day readmission after spine surgery. Spine J. 16, 1309-1314. https:// doi.org/10.1016/j.spinee.2016.06.012 (2016).

15. Modhia, U., Takemoto, S., Braid-Forbes, M. J., Weber, M. \& Berven, S. H. Readmission rates after decompression surgery in patients with lumbar spinal stenosis among Medicare beneficiaries. Spine 38, 591-596. https://doi.org/10.1097/BRS.0b013e31828628f5 (2013).

16. Passias, P. G. et al. Hospital readmission within 2 years following adult thoracolumbar spinal deformity surgery: prevalence, predictors, and effect on patient-derived outcome measures. Spine 41, 1355-1364. https://doi.org/10.1097/brs.000000000000155 2 (2016).

17. Pugely, A. J., Martin, C. T., Gao, Y. \& Mendoza-Lattes, S. Causes and risk factors for 30-day unplanned readmissions after lumbar spine surgery. Spine 39, 761-768. https://doi.org/10.1097/brs.0000000000000270 (2014).

18. Puvanesarajah, V. et al. Readmission rates, reasons, and risk factors in elderly patients treated with lumbar fusion for degenerative pathology. Spine 41, 1933-1938. https://doi.org/10.1097/brs.0000000000001631 (2016).

19. Roddy, E. \& Diab, M. Rates and risk factors associated with unplanned hospital readmission after fusion for pediatric spinal deformity. Spine J. 17, 369-379. https://doi.org/10.1016/j.spinee.2016.10.008 (2017).

20. Schairer, W. W. et al. Hospital readmission after spine fusion for adult spinal deformity. Spine 38, 1681-1689. https://doi. org/10.1097/BRS.0b013e31829c08c9 (2013).

21. Su, A. W. et al. Risk factors for 30-day unplanned readmission and major perioperative complications after spine fusion surgery in adults: a review of the national surgical quality improvement program database. Spine 41, 1523-1534. https://doi.org/10.1097/ brs.0000000000001558 (2016).

22. Wang, M. C. et al. Thirty-day readmissions after elective spine surgery for degenerative conditions among US Medicare beneficiaries. Spine J. 12, 902-911. https://doi.org/10.1016/j.spinee.2012.09.051 (2012).

23. Adogwa, O. et al. Racial disparities in 30-day readmission rates after elective spine surgery: a single institutional experience. Spine 41, 1677-1682. https://doi.org/10.1097/brs.0000000000001616 (2016).

24. Bozic, K. J. et al. The influence of procedure volumes and standardization of care on quality and efficiency in total joint replacement surgery. J. Bone Joint Surg. 92, 2643-2652. https://doi.org/10.2106/jbjs.I.01477 (2010).

25. Dailey, E. A., Cizik, A., Kasten, J., Chapman, J. R. \& Lee, M. J. Risk factors for readmission of orthopaedic surgical patients. J. Bone Joint Surg. 95, 1012-1019. https://doi.org/10.2106/jbjs.K.01569 (2013).

26. Kim, L., Kim, J. A. \& Kim, S. A guide for the utilization of health insurance review and assessment service national patient samples. Epidemiol. Health 36, e2014008. https://doi.org/10.4178/epih/e2014008 (2014).

27. Gruskay, J. A., Fu, M., Bohl, D. D., Webb, M. L. \& Grauer, J. N. Factors affecting length of stay after elective posterior lumbar spine surgery: a multivariate analysis. Spine J. 15, 1188-1195. https://doi.org/10.1016/j.spinee.2013.10.022 (2015).

28. Siemionow, K., Pelton, M. A., Hoskins, J. A. \& Singh, K. Predictive factors of hospital stay in patients undergoing minimally invasive transforaminal lumbar interbody fusion and instrumentation. Spine 37, 2046-2054. https://doi.org/10.1097/BRS.0b013 e31825c6688 (2012).

29. Wang, M. Y., Cummock, M. D., Yu, Y. \& Trivedi, R. A. An analysis of the differences in the acute hospitalization charges following minimally invasive versus open posterior lumbar interbody fusion. J. Neurosurg. Spine 12, 694-699. https://doi.org/10.3171/2009.12. Spine09621 (2010).

30. Adogwa, O. et al. 30-Day readmission after spine surgery: an analysis of 1400 consecutive spine surgery patients. Spine 42, 520-524. https://doi.org/10.1097/brs.0000000000001779 (2017).

31. Cusimano, M. D., Pshonyak, I., Lee, M. Y. \& Ilie, G. A systematic review of 30-day readmission after cranial neurosurgery. J. Neurosurg. 127, 342-352. https://doi.org/10.3171/2016.7.Jns152226 (2017).

32. Khanna, R. et al. Utility of readmission rates as a quality of care measure and predictors of readmission within 30 days after spinal surgery: a single-center, multivariate analysis. Spine 40, 1769-1774. https://doi.org/10.1097/brs.0000000000001146 (2015).

33. Bernatz, J. T. \& Anderson, P. A. Thirty-day readmission rates in spine surgery: systematic review and meta-analysis. Neurosurg. Focus 39, E7. https://doi.org/10.3171/2015.7.Focus1534 (2015).

34. Saravay, S. M., Pollack, S., Steinberg, M. D., Weinschel, B. \& Habert, M. Four-year follow-up of the influence of psychological comorbidity on medical rehospitalization. Am. J. Psychiatry 153, 397-403. https://doi.org/10.1176/ajp.153.3.397 (1996).

35. Marcantonio, E. R. et al. Factors associated with unplanned hospital readmission among patients 65 years of age and older in a Medicare managed care plan. Am. J. Med. 107, 13-17 (1999).

36. Mlodinow, A. S. et al. Predictors of readmission after breast reconstruction: a multi-institutional analysis of 5012 patients. Ann. Plast. Surg. 71, 335-341. https://doi.org/10.1097/SAP.0b013e3182a0df25 (2013).

37. Manilich, E. et al. Key factors associated with postoperative complications in patients undergoing colorectal surgery. Dis. Colon Rectum 56, 64-71. https://doi.org/10.1097/DCR.0b013e31827175f6 (2013).

38. Anandasivam, N. S. et al. Access of patients with lumbar disc herniations to spine surgeons: the effect of insurance type under the affordable care act. Spine 42, 1179-1183. https://doi.org/10.1097/brs.0000000000002005 (2017).

39. Lindenauer, P. K. et al. Income inequality and 30 day outcomes after acute myocardial infarction, heart failure, and pneumonia: retrospective cohort study. BMJ 346, f521. https://doi.org/10.1136/bmj.f521 (2013).

\section{Acknowledgements}

It is a pleasure to convey my gratitude to the people who contributed in different ways to the research. Foremost, I thank all the participants of this research for their effort and time to help with this research. I would like to thank Yonsei University Health System for providing me an opportunity to work on this project. This work was supported by the Korea Health Technology R\&D Project through the Korea Health Industry Development Institute (KHIDI), funded by the Ministry of Health \& Welfare, Republic of Korea under Grant [Number HC15C1320].

\section{Author contributions}

P.G.C. and H.L. wrote the main manuscript text. T.H.K. and G.Y.J. were in charge of statistical analysis. S.H.P. prepared Fig. 1. All authors reviewed the manuscript.

\section{Competing interests}

The authors declare no competing interests. 


\section{Additional information}

Correspondence and requests for materials should be addressed to D.A.S.

Reprints and permissions information is available at www.nature.com/reprints.

Publisher's note Springer Nature remains neutral with regard to jurisdictional claims in published maps and institutional affiliations.

(c) (1) Open Access This article is licensed under a Creative Commons Attribution 4.0 International License, which permits use, sharing, adaptation, distribution and reproduction in any medium or format, as long as you give appropriate credit to the original author(s) and the source, provide a link to the Creative Commons license, and indicate if changes were made. The images or other third party material in this article are included in the article's Creative Commons license, unless indicated otherwise in a credit line to the material. If material is not included in the article's Creative Commons license and your intended use is not permitted by statutory regulation or exceeds the permitted use, you will need to obtain permission directly from the copyright holder. To view a copy of this license, visit http://creativecommons.org/licenses/by/4.0/.

(c) The Author(s) 2020 